\title{
MicroRNA profiling of dogs with transitional cell carcinoma of the bladder using blood and urine samples
}

\author{
Michael S. Kent ${ }^{1}$, Allison Zwingenberger', Jodi L. Westropp², Laura E. Barrett ${ }^{3}$, Blythe P. Durbin-Johnson ${ }^{4}$, \\ Paramita Ghosh ${ }^{5,6,7^{*}}$ and Ruth L. Vinall $\|^{5,6,8^{*}}$ (D)
}

\begin{abstract}
Background: Early signs of canine transitional cell carcinoma (TCC) are frequently assumed to be caused by other lower urinary tract diseases (LUTD) such as urinary tract infections, resulting in late diagnosis of TCC which could be fatal. The development of a non-invasive clinical test for TCC could dramatically reduce mortality. To determine whether microRNAs (miRNAs) can be used as non-invasive diagnostic biomarkers, we assessed miRNA expression in blood and/or urine from dogs with clinically normal bladders $(n=28)$, LUTD $(n=25)$, and TCC $(n=17)$. Expression levels of 5 miRNA associated with TCC pathophysiology (miR-34a, let-7c, miR-16, miR-103b, and miR-106b) were assessed by quantitative real-time PCR.

Results: Statistical analyses using ranked ANOVA identified significant differences in miR-103b and miR-16 levels between urine samples from LUTD and TCC patients (miR-103b, $p=0.002$; and miR-16, $p=0.016$ ). No statistically significant differences in miRNA levels were observed between blood samples from LUTD versus TCC patients. Expression levels of miR-34a trended with miR-16, let-7c, and miR-103b levels in individual normal urine samples, however, this coordination was completely lost in TCC urine samples. In contrast, co-ordination of miR-34a, miR-16, let-7c, and miR-103b expression levels was maintained in blood samples from TCC patients.

Conclusions: Our combined data indicate a potential role for miR-103b and miR-16 as diagnostic urine biomarkers for TCC, and that further investigation of miR-103b and miR-16 in the dysregulation of coordinated miRNA expression in bladder carcinogenesis is warranted.
\end{abstract}

Keywords: microRNA, Canine bladder cancer, Urine and blood analysis

\section{Background}

Transitional cell carcinoma (TCC) is the most common bladder tumor in dogs representing approximately $2 \%$ of all canine tumors [1-3]. Further, the prevalence of this disease is increasing $[4,5]$. The recognized causes of TCC are varied with identified risk factors including use of topical insecticides, living in houses where the yards have been treated with insecticides, and living near marshes sprayed for mosquitoes or industrial areas [6, 7]. Female dogs and obese dogs appear to have an increased incidence of disease, in contrast to humans where the

\footnotetext{
* Correspondence: paghosh@ucdavis.edu; rvinall@cnsu.edu

${ }^{5}$ Department of Urology, University of California, Davis, School of Medicine, Sacramento, CA, USA

Full list of author information is available at the end of the article
}

disease is more prevalent among male patients [3, 7]. There are also several breed predilections for TCC, including Scottish terriers, beagles, Shetland sheep dogs, wire fox terriers and West Highland white terriers, suggesting a genetic component to this disease $[4,8]$.

The extent of tumor locally as well as locoregional and distant metastasis is staged using the Tumor, Lymph Node and Metastasis (TNM) staging system [9]. Most dogs are diagnosed with TCC later in the course of disease with higher stage tumors being most common [10]. It has also been shown that having a higher stage of disease can negatively affect response to treatment. Treatment for TCC involves the use of surgery, radiotherapy, nonsteroidal anti-inflammatory agents and chemotherapy. Even with aggressive therapy, most dogs 
fail treatment and die from their disease [3, 11-17]. Some of the biggest gains in survival in human cancer medicine have occurred because of early detection of disease. This has proven true for prostate cancer, breast cancer and colon cancer as well as TCC. While $~ 80 \%$ of human patients present with superficial TCC, $10-30 \%$ of these patients will progress to invasive TCC and frequent screening has allowed for earlier detection of progression and has helped improve outcomes including survival [18-20]. Given this, early detection of TCC in dogs is likely to impact their response and survival.

Currently the diagnosis of TCC is most commonly made after dogs show advanced signs of disease, including hematuria, stranguria, and pollakiuria, all of which can mimic lower urinary tract disease (LUTD) [1]. Abdominal ultrasound may reveal structural changes to the urinary bladder, but lacks specificity and is also relatively expensive $[4,21]$. Aspirates and open surgical biopsy of bladder tumors carry the risk of distant seeding of tumor cells [22, 23]. Other methods of definitive diagnosis, including traumatic catheterization and cystoscopically obtained biopsies, carry their own risks of complication and associated costs, making their use as a screening tool impractical [21]. The V-BTA rapid latex agglutination urine dipstick test to detect dogs with TCC proved not to be useful due to a low positive predictive value, resulting in only $3 \%$ of positive tests occurring in dogs with TCC $[4,24]$. This indicates the need for an improved diagnostic screening test to detect dogs with TCC vs LUTD.

MicroRNAs (miRNAs) are small, highly stable, noncoding RNAs which facilitate post-transcriptional control of gene expression [25]. Multiple studies have demonstrated that dysregulation of miRNA expression levels can play a functional role in the initiation and progression of many cancers, and that miRNA can be used as diagnostic, prognostic, and predictive biomarkers [26]. Importantly, miRNA are relatively stable in most body fluids meaning they have the potential to be used clinically as non-invasive biomarkers [27-29]. The majority of miRNA biomarker discovery studies have focused on assessing miRNA levels in blood, and several bloodbased miRNA biomarkers are currently in development. Assessment of miRNA levels in urine is possible but has proved much more challenging due to accelerated RNA degradation as a result of RNA being in an acidic environment [30-32]. As urine is in direct contact with the bladder (and bladder cancers, if present), urine samples are more likely than blood samples to contain miRNA which are derived from bladder cells and therefore any alterations in miRNA expression which are observed in urine samples are likely to reflect actual changes in miRNA expression which are occurring in bladder cells.

Altered expression of several miRNA has been observed in human bladder cancer progression [33-37].
We previously determined that assessment of miRNA in canine tissue specimens can be used to distinguish between inflammatory disease and TCC [38]; a statistically significant difference in expression levels of miR-34a, miR-16, miR-103b and miR-106b was observed between tissue specimens from canine LUTD and TCC patients. All of these miRNA have the ability to control expression of molecules which play a role in driving human bladder cancer initiation and progression, including components of the $\mathrm{p} 53, \mathrm{Rb}$ and/or Bcl-2 signaling pathways and likely play a role in driving bladder carcinogenesis in canines [39-45]. In addition, we recently demonstrated that the miRNA let-7c plays an important role in the response of human patients with bladder cancer to chemotherapy [46]. Based on these results, the goal of the current study was to determine whether assessment of these same miRNA is feasible in canine blood and urine samples, and whether these miRNA show potential for use as non-invasive biomarkers which can distinguish between non-neoplastic LUTD, such as urinary tract infections (UTI) and cystic calculi, and $\mathrm{TCC}$, in canine patients.

The development of a non-invasive method versus an invasive method to distinguish between common inflammatory LUTD and TCC in canine patients is highly desirable for both economical and feasibility reasons and could have implications for human medicine $[30-32,47,48]$.

\section{Methods}

\section{Patient samples}

Dogs with newly diagnosed, untreated transitional cell carcinoma of the urinary bladder and two control groups, clinically normal dogs and dogs with nonneoplastic lower urinary tract disease (such as dogs with UTI and cystic calculi), were entered into the study.

\section{Definitions of disease}

A clinically normal dog was defined as a dog with no lower urinary tract signs, a normal bladder on ultrasound examination done by a board certified veterinary radiologist, a normal urinalysis and a negative urine culture result. Dogs were only enrolled if they were not receiving any antibiotics, non-steroidal or steroidal medications. Dogs with inflammatory or infectious lower urinary tract disease were defined as dogs with a positive urine culture and/or urolithiasis and no bladder mass seen under ultrasound evaluation, during surgical exploration of the bladder or during cystoscopy. Dogs with TCC were defined as dogs having either a histopathological or cytological diagnosis of transitional cell carcinoma. Only dogs not receiving any treatment for this disease including chemotherapy, non-steroidal antiinflammatory medications or antibiotics at the time of 
sampling could be enrolled. As part of the study design, the person performing the molecular analyses was blinded as to the group inclusion of the sample until after sample analyses were complete.

\section{Analysis of canine blood}

$2.5 \mathrm{mls}$ of whole blood was obtained from the jugular vein of each dog and placed in a PAXgene RNA Blood collection tube (Qiagen - Cat\# 762165). PAXgene tubes were then inverted 8-10 times and stored at room temperature (20C) for $2 \mathrm{~h}$ before being transferred to $-20 \mathrm{C}$ for $24 \mathrm{~h}$. After $24 \mathrm{~h}$, the tubes were transferred to $-80 \mathrm{C}$ and stored until the time of analysis. The PAXgene blood miRNA kit (PreAnalytiX - Cat\# 762165) was used to isolate RNA from blood samples per manufacturer's instructions. To allow for normalization during subsequent $\mathrm{qPCR}$ analysis, a synthetic RNA was added to RNA preps $\left(5.6 \times 10^{8}\right.$ copies of cel-miR-39 (Qiagen, Cat\# 217184) per sample). This is a well accepted method for normalization [49].

\section{Analysis of canine urine}

$10 \mathrm{mls}$ of urine was collected by ultrasound guided antepubic cystocentesis. $3 \mathrm{mls}$ was submitted for urinalysis, $2 \mathrm{mls}$ was used for urine culture, and $5 \mathrm{mls}$ was stored in $1 \mathrm{ml}$ aliquots at $-80{ }^{\circ} \mathrm{C}$ until the time of analysis. Prior to RNA extraction, urine was thawed on ice then centrifuged at 250xG for $5 \mathrm{~min}$ to pellet exfoliated cells present in the urine. The Qiagen miRNeasy kit (Qiagen - Cat\# 217004) was used to extract RNA from cell pellets.

\section{miRNA analysis}

RNA extracted from blood and urine extractions was quantified using a NanoDrop 2000 spectrophotometer. Relative expression levels of miR-34a, let-7c, miR-16, miR-103b, and miR-106b were assessed using predesigned TaqMan primer/probes sets (Applied Biosystems) in combination with the TaqMan MicroRNA Reverse Transcription and Universal PCR Master Mix (no AmpErase UNG) kit (Applied Biosystems, Cat\# 4324018) per manufacturer's protocol. Three replicates were included for each sample. Twenty nanograms of total RNA was used for each RT reaction. Cel-miR-39 expression levels were assessed to allow for normalization of miRNA expression in blood samples. To allow for normalization of miRNA expression in urine samples, RNU6 expression levels were assessed using predesigned TaqMan primer/probes sets (Applied Biosystems)). RNU6 is frequently used as an endogenous control gene for miRNA expression studies [50]. Expression values of miR-34a, let-7c, miR-16, miR-103b, and miR-106b are expressed relative to these normalization controls using the 2(-delta delta cycle threshold) method.

\section{Statistical analysis}

We determined that inclusion of 20 normal, 20 LUTD, and 17 TCC patients would provide a power of 0.8 for our study (28 normal, 25 LUTD, and 17 TCC patients were included in the actual study). Data from each of the groups were graphed and parametric and/or nonparametric analyses performed to generate descriptive and inferential statistical data using a commercially available software program (GraphPad Prism, GraphPad Software, La Jolla, CA). The following variables were assessed in this study; age (continuous variable), weight (continuous variable), miRNA levels (miR-34a, let-7c, miR-16, miR-103b, miR-106b, continuous variable), gender (categorical variable (male/female)), presence of cystic calculi (categorical variable (yes/no)), presence of UTI (categorical variable (yes/no)). The Chi-squared test was used to determine whether differences in patient characteristics existed between groups for gender, while standard ANOVA was used to determine whether differences in age, weight, and amount of miRNA isolated from patient blood and urine specimens existed between groups. MiRNA expression levels were compared between groups using Kruskal-Wallis One Way ANOVA on Ranks (Ranked ANOVA), a method which is becoming common place in biomarker discovery studies because it is able to take into account the different levels of variation which are present in the groups being assessed [51-56]. It is of note that this type of analysis is considered exploratory in nature, i.e. is used for hypothesis-generation. Correlation between miRNA expression in the 3 patient groups was estimated by Pearson Product moments analysis. Statistical significance for all tests was set at $p<0.05$.

\section{Results}

\section{Patient characteristics}

A total of 70 dogs, including 28 normal control dogs, 25 dogs with LUTD and 17 dogs with TCC were included in the study (Table 1). A statistically significant difference in mean age was observed between the groups (Table $1, P<0.0001)$. Statistically significant differences in gender and weight were not observed (Table 1). In the normal control group there were 11 male castrated dogs and 17 female spayed dogs. In the LUTD control group there were 11 male castrated dogs, 1 intact male dog, 10 female spayed dogs and 3 intact female dogs. In the TCC group there were 9 male castrated dogs and 8 female spayed dogs. In the normal control group there were 15 mixed breed dogs, 3 Labrador retrievers, 2 border collies, 2 dachshunds and 1 each of 6 different pure bred dogs. All had negative urine cultures results and all had no evidence of LUTD on abdominal ultrasound. In the LUTD group there were 5 mixed breed 
Table 1 Patient Characteristics

\begin{tabular}{|c|c|c|c|c|}
\hline \multirow[t]{2}{*}{ \# Patients } & Normal control & Dogs with LUTD & Dogs with TCC & \multirow[t]{2}{*}{$p$-value } \\
\hline & 28 & 25 & 17 & \\
\hline \multicolumn{5}{|l|}{ Gender } \\
\hline Male & $11(39.3 \%)$ & $12(48 \%)$ & $9(53 \%)$ & $>0.5$ \\
\hline Female & $17(60.7 \%)$ & $13(52 \%)$ & $8(47 \%)$ & $>0.5$ \\
\hline \multicolumn{5}{|l|}{ Characteristics } \\
\hline Mean Age (Range) years & $5.2 \pm 2.98(0.67-12.0)$ & $7.5 \pm 3.9(0.5-14.0)$ & $10.0 \pm 2.4(6-14)$ & $<0.0001$ \\
\hline Mean Weight (Range) Kg & $17.85 \pm 10.9(3.4-40.0)$ & $14.15 \pm 12.16(2.9-50.0)$ & $20.97 \pm 15.37(5.1-69.0)$ & $>0.5$ \\
\hline \multicolumn{5}{|l|}{ Disease } \\
\hline Cystic Calculi (CC) & 0 & 11 & 0 & \\
\hline Urinary Tract infection (UTI) & 0 & 2 & 3 & \\
\hline$C C+U T I$ & 0 & 11 & 0 & \\
\hline TCC based on biopsy & 0 & 0 & 5 & \\
\hline TCC based on cytology & 0 & 0 & 12 & \\
\hline
\end{tabular}

dogs, 3 Bishon Frises, 2 pit bull terriers and 1 each of 14 different pure bred dogs. For the dogs with LUTD, 11 were diagnosed with cystic calculi, 11 were diagnosed with both cystic calculi and a urinary tract infection based on a positive aerobic bacterial urine culture, and 2 were diagnosed with chronic urinary tract infections. In the TCC group there were 4 mixed breed dogs, 2 Australian shepherds, 2 German shepherd dogs, 2 West Highland white terriers and 1 each of 7 different pure bred dogs. Five were diagnosed on biopsy and 12 were diagnosed on cytology. All dogs were assumed to have muscle invasive disease based on appearance on ultrasound examination but as not all dogs had biopsies taken this could not be fully evaluated. Three had a concurrent urinary tract infection based on results of aerobic bacterial urine cultures.

\section{Extraction of miRNA from canine urine and blood samples}

Based on recent publications comparing the levels of miRNA in blood and urine of bladder cancer patients [57-59], we assessed both blood and urine samples. Bladder cells are in direct contact with urine and as a number of the cells present in urine are of urothelial origin; the higher content of bladder cells in urine versus blood makes it more likely that observed changes in miRNA expression in urine samples are reflective of alterations that directly mediate bladder inflammation or TCC.

We chose to isolate RNA from cells present in urine samples rather than isolate RNA which is present 'free' in the urine because other studies have demonstrated isolating sufficient amounts of high quality 'free' RNA from urine is challenging due to low $\mathrm{pH}$ and high levels of nucleases [30-32]. The median quantities of RNA isolated from cells present in canine patient urine samples from the three groups were: $181.6 \mathrm{ng}$ (Normal patients, range; $70.8 \mathrm{ng}-760.4 \mathrm{ng}, n=28)$, $938.6 \mathrm{ng}$ (LUTD patients, range; $93.6 \mathrm{ng}-42,337.6, n=20$ ), 1192.4 ng (TCC patients, range; $117.6 \mathrm{ng}-55,468.8 \mathrm{ng}$, $n=11$ ) (Fig. 1A). There was not a statistically significant difference in the quantity of RNA isolated from the 3 patient groups.

The Qiagen PAXGene kit was used to isolate RNA from canine blood samples. The median quantities of RNA isolated from canine patient blood samples from the three groups were: $1839.8 \mathrm{ng}$ (Normal patients, range; $320 \mathrm{ng}-9510.8 \mathrm{ng}, \mathrm{n}=28$ ), $1999.2 \mathrm{ng}$ (LUTD patients, range; $12.4 \mathrm{ng}-7279.6 \mathrm{ng}, n=25), 1887.2 \mathrm{ng}$ (TCC patients, range; $146.4 \mathrm{ng}-8636.6 \mathrm{ng}, n=17$ ) (Fig. 1B). There was not a statistically significant difference in the quantity of RNA isolated from the 3 groups.

A statistically significant difference in RNA yields from blood versus urine samples collected from normal patients was observed ( $p=0.0001,10$-fold difference), however, there was not a statistically significant difference in RNA yield for LUTD or TCC patients (Fig. 1A, B).

\section{Age-related differences in miR-34a expression in normal dogs and those with LUTD but not TCC}

Expression of 5 miRNAs associated with TCC pathophysiology (miR-34a, let-7c, miR-16, miR-103b, and miR-106b) [38, 60], was assessed in RNA extracted from clinically normal, LUTD, and TCC canine blood and urine samples using quantitative real time PCR. Since a statistically significant difference in age was observed between dogs with normal bladder, LUTD and TCC (Table 1), we first investigated whether any age-related differences in miRNA expression were observed in the three patient groups (Fig. 2). There 

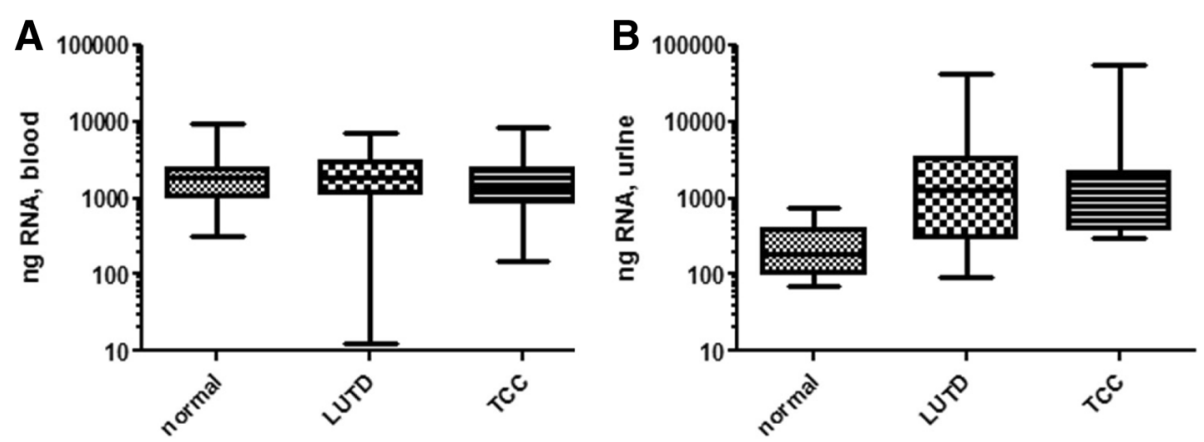

Fig. 1 Relative quantities of RNA extracted from blood and urine specimens from canine patients with normal bladder, lower urinary tract disease (LUTD), and transitional cell carcinoma (TCC) of the bladder. Statistically significant differences in the quantity of RNA isolated from blood specimens (a) or urine specimens (b) from the 3 patient groups were not observed. However, there was a statistically significant difference in the quantity of RNA isolated from blood versus urine from patients with normal bladders $(p=0.0001)$. No statistically significant difference was observed in quantity of RNA isolated from blood versus urine from patients with LUTD, or patients with TCC. Standard ANOVA was used for these comparisons

were no age-related differences observed in either let7c, miR-16, miR-103b or miR-106b in urine or blood samples, however, urine miR-34a expression correlated strongly with age in both the normal group and the LUTD group, but not in the TCC group (Fig. 2). Correlation between age and miR-34a was not observed in blood samples. Neither gender nor body weight correlated with the expression of any of the miRNA tested (data not shown). It is possible that suppression of miR-34a expression may occur in aging TCC patients. Age-matched control studies will be necessary to confirm this.

\section{Paired analysis of miRNA expression in patient urine samples demonstrate that miR-34a correlations with other miRNAs are disrupted in TCC}

As several of the miRNAs analyzed in this study target the same molecules and/or same signaling pathways (miR-34a targets; Bcl-2, CCND1, CDK4/6, CREB, DLL1, E2F3, MET, c-MYC, SIRT-1, HMGA2, Notch1, Let-7c targets; LIN28, Ras, HMGA2, c-myc, Bcl-xL, miR-16 targets; BCL2, MCL1, CCND1, WNT3A; miR-103b targets; CCNE1, CDK2, CREB1, miR-106b targets; CCND1, E2F3, RBL1/2, WEE1, [24-30]), we rationalized that there may be a correlation between their relative expression levels in individual patient specimens. We used Pearson Product Moment Correlation to assess the correlation between individual miRNA in urine and blood (Additional file 1: Tables S1-S6). In blood specimens from normal, LUTD, and TCC patients, expression levels of all 5 miRNA analyzed trended together in individual patients. In urine samples from normal patients, expression of miR-34a trended with let-7c, miR-16, and miR-103b, but not miR-106b (Fig. 3A). In urine samples from LUTD patients, expression of miR-34a trended with let-7c and miR-103b but not miR-16 or miR-106b (Fig. 3B). In urine from TCC patients, miR-34a expression was completely independent of let-7c, miR16, miR-103b, and miR-106b (Fig. 3C). Thus, miR-34a correlation with the other miRNAs examined decreased from normal $>$ LUTD $>$ TCC. Conversely, miR-16 was not correlated with miR-103b or miR-106b in urine from normal canine but significant correlation was observed in the diseased states. These data indicate that alteration of coordinated expression of miRNAs occurs in patients with LUTD and TCC. It is noteworthy that no correlation between miRNA expression and RNA yield was observed in any of these settings.

MiRNA expression levels in normal, LUTD, and TCC blood and urine samples

Next, we investigated whether any of the miRNA tested were differentially expressed in blood and urine samples from normal dogs and those with LUTD or TCC. Kruskal-Wallis one-way ANOVA on ranks (ranked ANOVA), an exploratory non-parametric method that is frequently used in biomarker discovery studies [51-56], was used for these analyses. No significant differences in expression of miR-34, let-7c, miR-16, or miR-106b were observed in blood samples from the three groups (Fig. 4A-C, E, Table 2), however, one-way ANOVA on ranks identified statistically significant differences in the expression levels of miR$103 \mathrm{~b}$ in the blood of normal vs LUTD $(p=0.028)$ and normal vs TCC patients $(p=0.011)$, but not LUTD vs TCC patients $(p>0.05)$ (Fig. 4D, Table 2).

We also examined the levels of miRNA in urine from these three groups of patients (Fig. 5, Table 2). As in blood samples, there was no significant difference in miR-34a levels in the urine of animals from the three groups (Fig. 5A). A statistically significant difference in miR-106b levels in the urine of normal vs TCC patients (Fig. 2E, $\mathrm{p}<0.001$ ) was observed. Comparison of patients with LUTD and TCC determined that only miRNA-16 


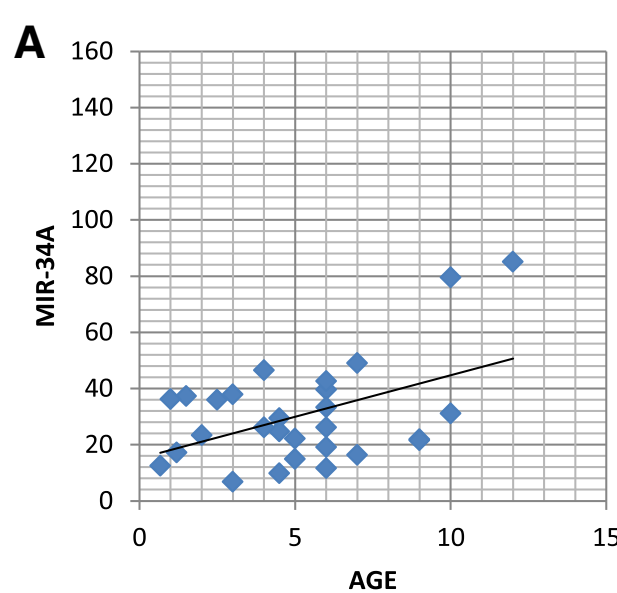

\author{
PPM $=0.469$ \\ $\mathrm{p}=0.0117$ \\ $\mathrm{N}=28$ \\ Normal Urine miR-34a \\ - Linear (Normal Urine \\ miR-34a)
}

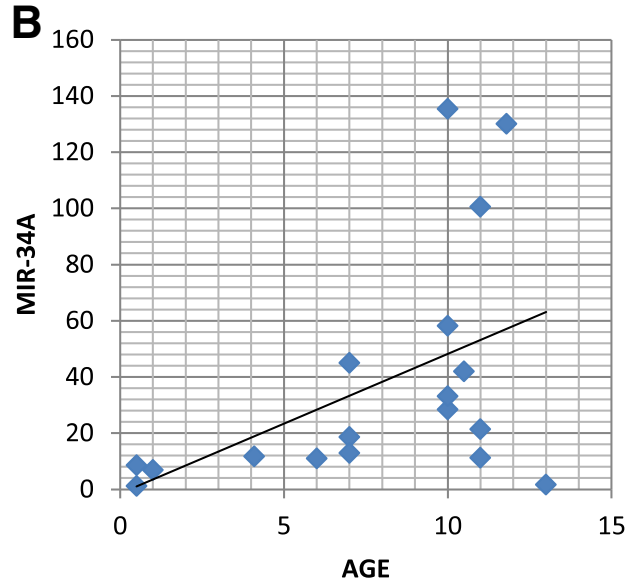

PPM $=0.469$

$\mathrm{p}=0.0494$

$\mathrm{N}=18$

- LUTD Urine miR-34a

— Linear (LUTD Urine miR-34a)

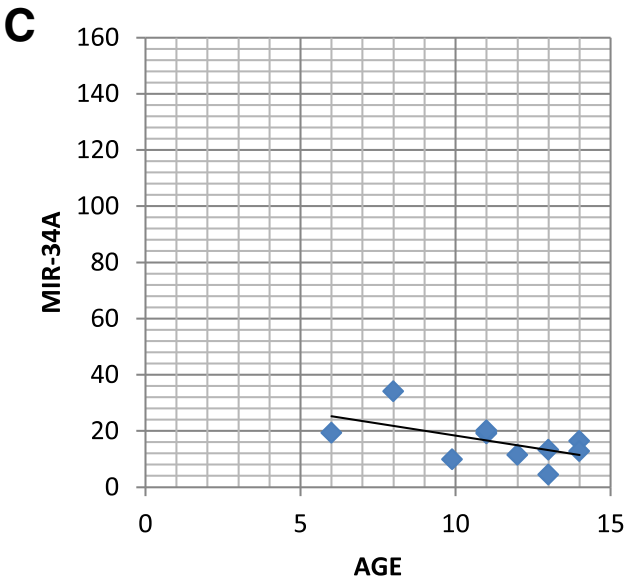

$P P M=-0.561$

$\mathrm{p}=0.0726$

$\mathrm{N}=11$

TCC Urine miR-34a

L Linear (TCC Urine miR-

34a)

Fig. 2 Age-related differences in miR-34a expression exist in urine samples from normal dogs and those with lower urinary tract disease (LUTD) but not in urine samples from dogs with transitional cell carcinoma (TCC) of the bladder. Urine miR-34a expression correlated strongly with age in both the normal group (a) and the LUTD group (b), but not in the TCC group (c). There were no age-related differences observed in let-7c, miR-16, miR-103b, or miR-106b expression (data not shown). A correlation between age and miRNA expression was not observed in canine blood samples (data not shown). Pearson Product Moment Correlation was used to generate these data

$(p=0.016)$ and miR-103b $(p=0.002)$ appeared to have any significant differences (Fig. 5C, D, Table 2). Thus, these two miRNAs are potential candidates for distinguishing biomarkers of TCC vs LUTD.

\section{Discussion}

There is a clinical need to develop non-invasive and inexpensive tests that have fast turnaround to distinguish between canine patients with non-neoplastic LUTD and 


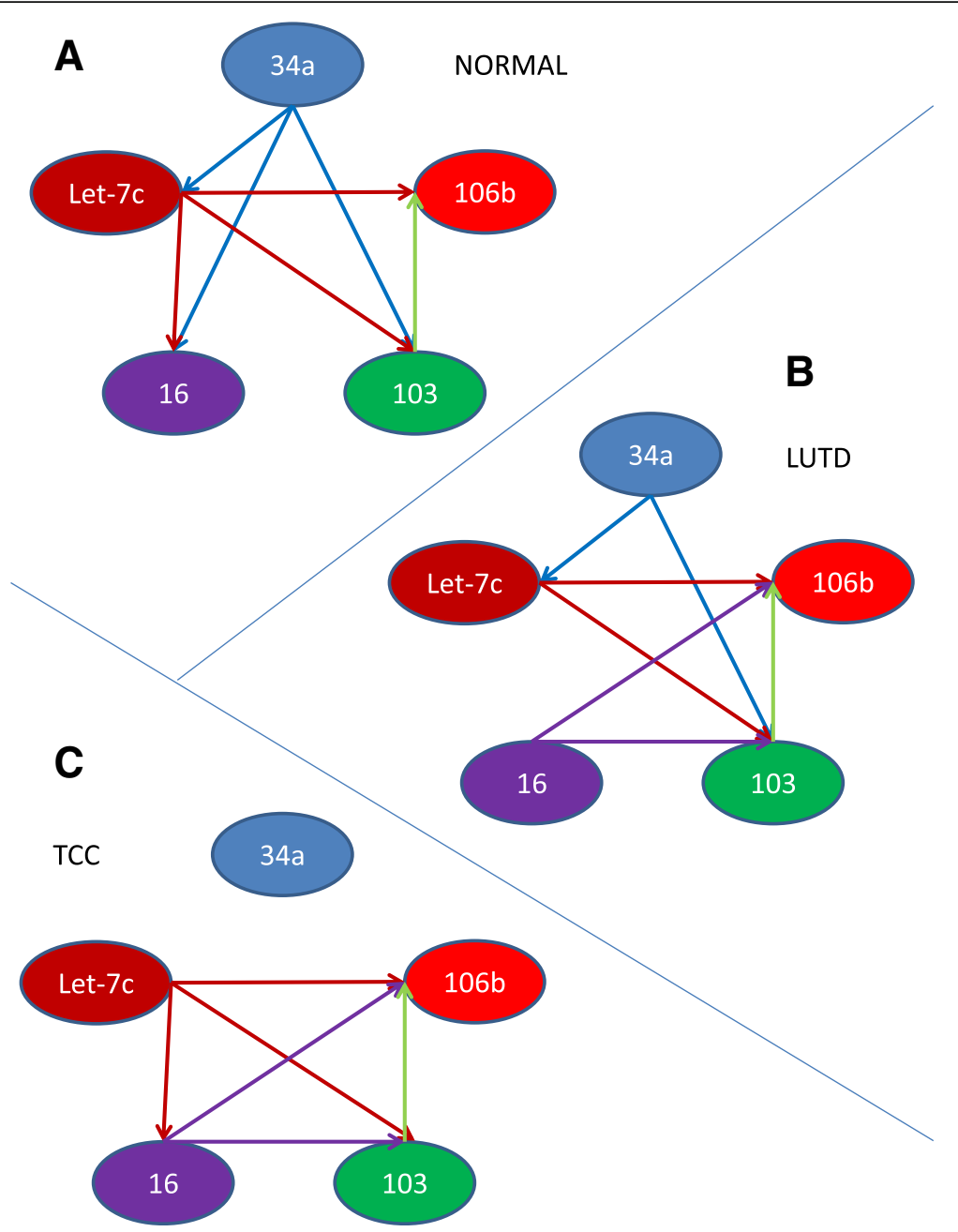

Fig. 3 The correlation of miR-34a expression with other miRNAs is disrupted in TCC. In urine samples from normal and LUTD patients, expression of miR-34a trended with other related miRNA: let-7c, miR-16, and miR-103b, but not miR-106b (a). MiR-34a expression was independent of miR-16 in LUTD patients (b), and completely independent of any other miRNA tested in TCC (c). Thus, miR-34a correlation with the related miRNAs examined decreased normal > LUTD > TCC. In blood specimens from normal, LUTD, and TCC patients, expression levels of all 5 miRNA analyzed trended together in individual patients (data not shown)

canine patients with TCC. The goal of this study was to determine whether assessment of miRNA expression in canine urine and blood samples is possible and could help address this need. We successfully assessed expression of five miRNA (miR-34a, let-7c, miR-16, miR-103b, and miR-106b) in canine urine and blood samples. Analysis of miRNA in canine urine has not previously been reported. Statistically significant differences in miR-103b $(p=0.002)$ and miR-16 $(p=0.016)$ expression levels were observed in canine urine specimens from LUTD versus TCC patients, however, no difference in miRNA expression levels was observed in canine blood specimens from these 2 groups. It should be noted that this study was exploratory in nature and a larger prospective study will be necessary to validate the association of miR-103b and miR-16 expression levels with canine TCC. It should also be noted that while it has been shown that some dog breeds are predisposed to TCC [3] this study was not powered to detect whether miRNA expression contributes to these predispositions and there were too few of any one breed in the TCC and control groups to attempt meaningful analysis. Lastly, the study was not powered to determine whether these miRNA are expressed early in the course of disease or only after they progress to become muscle invasive. More work is need to determine if these miRNA are associated with earlier superficial forms of the disease.

To our knowledge, this is the first study to observe differential expression of miR-103b and miR-16 in body fluids from canine bladder cancer patients versus patients with LUTD. Jiang et al. very recently reported lower miR-103b expression levels predict worse outcome 

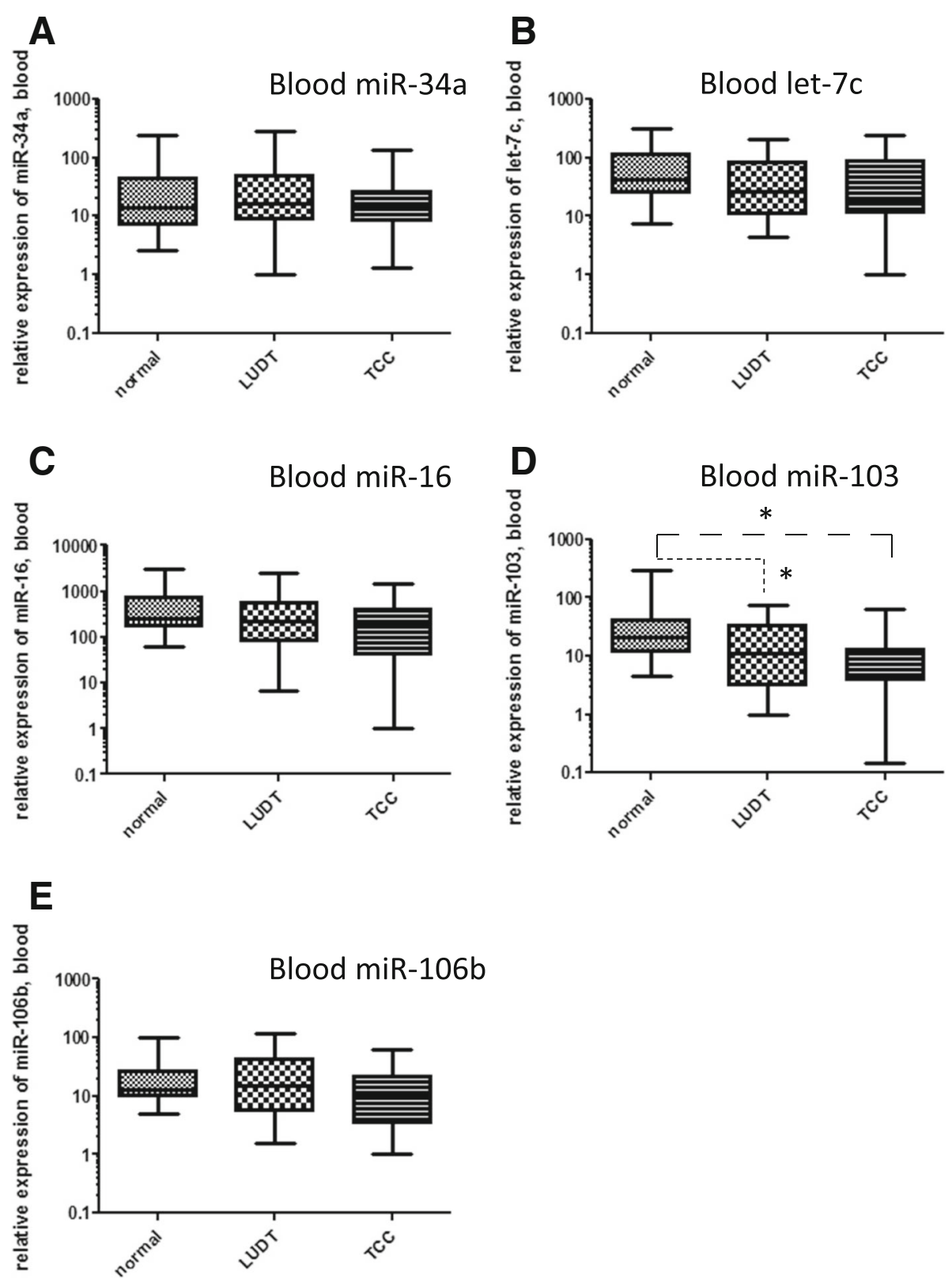

Fig. 4 Comparison of expression levels of miR-34a, let-7c, miR-16, miR-103b, and miR-106b in blood specimens from patients with normal bladders, lower urinary tract disease (LUTD), and transitional cell carcinoma (TCC) of the bladder. One-way ANOVA on ranks identified statistically significant differences in the expression levels of miR-103b in the blood of normal vs LUTD $(p=0.028)$ and normal vs TCC patients $(p=0.011)$, but not LUTD vs TCC patients $(p>0.05)$ (d). No statistically significant differences in expression levels were observed between the 3 patient groups for miR-34a, let-7c, miR-16, or miR-106b (a, b, c, and $\mathbf{e})$

for humans with muscle invasive bladder cancer [61]. This group assessed miR-103b expression in human blood but not urine samples. It is possible lack of statistical power is a reason why we did not observe differences of miR-103b in canine blood samples in addition to urine samples. In addition, the genetics of the human bladder may be different from that of canine bladder. MiR-103b has been shown to target several molecules which play a role in carcinogenesis in other cell types, for example CCNE1, CDK2, CREB1, DICER, and PTEN [62] [44], and colorectal cancer cell line studies indicate dysregulation of miR-103b expression can drive cancer progression [62-64]. In addition to validating miR-103b as a non-invasive biomarker to distinguish between canine LUTD and TCC, our future studies will focus on identifying downstream targets of miR-103b in bladder cancer cells and the impact of miR-103b on bladder cancer cell growth and survival; it is possible that miR-103b 
Table 2 Median values of miRNA from blood and urine of dogs with normal bladders, LUTD and TCC and one-way ANOVA on ranks analysis

\begin{tabular}{|c|c|c|c|c|c|c|}
\hline \multirow[t]{3}{*}{ Age } & \multicolumn{3}{|c|}{ MEDIAN VALUES } & \multicolumn{3}{|c|}{$p$-values (one-way ANOVA on ranks) } \\
\hline & NORMAL & LUTD & TCC & NORMAL vs LUTD & NORMAL Vs TCC & LUTD vs TCC \\
\hline & 5 & 7 & 11 & 0.0371 & $<0.001$ & 0.002 \\
\hline Blood miR-34a & 13.882 & 16.393 & 15.047 & $>0.05$ & $>0.05$ & $>0.05$ \\
\hline Blood Let-7c & 41.478 & 26.022 & 19.420 & $>0.05$ & $>0.05$ & $>0.05$ \\
\hline Blood miR-16 & 247.180 & 223.006 & 211.826 & $>0.05$ & $>0.05$ & $>0.05$ \\
\hline Blood miR-103b & 21.427 & 11.097 & 11.757 & 0.028 & 0.011 & 0.709 \\
\hline Blood miR-106b & 12.663 & 14.910 & 10.452 & $>0.05$ & $>0.05$ & $>0.05$ \\
\hline Urine miR-34a & 26.152 & 19.947 & 16.305 & $>0.05$ & $>0.05$ & $>0.05$ \\
\hline Urine Let-7c & 36.801 & 5.603 & 1.788 & $<0.001$ & $<0.001$ & 0.092 \\
\hline Urine miR-16 & 37.730 & 64.643 & 21.398 & 0.066 & 0.095 & 0.016 \\
\hline Urine miR-103b & 8.539 & 5.199 & 2.038 & 0.298 & $<0.001$ & 0.002 \\
\hline Urine miR-106b & 8.380 & 6.623 & 2.923 & 0.276 & 0.001 & 0.063 \\
\hline
\end{tabular}

may have utility as a therapeutic target as well as a diagnostic biomarker. The targets of miR-16 in bladder cancer cells have not been determined and its impact on bladder cancer cell growth and survival remains unknown, however, studies in other cancer cell types, including chronic lymphocytic lymphoma (CLL) and prostate cancer, have demonstrated dysregulation of miR-16 expression is associated with cancer initiation and/or progression [65-67]. The loss of correlation of miR-34a expression with age in TCC patients as well as the loss of coordinated expression of miR-34a with let7c, miR-103b, and miR-106b (a progressive loss of miR34a coordination with these miRNA was observed from normal > LUTD > TCC patients), indicates miR-34a may also contribute to bladder carcinogenesis. Coordinated control of miRNA expression has been shown to be important in many biological systems to allow for the regulation of complex cellular processes and can occur through genomic clustering, epigenetic regulation, or regulation by a shared transcription factor $[68,69]$. In vitro studies will be necessary to determine how dysregulation of coordinated miRNA expression occurs in bladder cancer cells and how this contributes to carcinogenesis.

Key differences were observed between our current study and a prior study in which we assessed expression of miR-106b, miR-34a, miR-16, and miR-103b, and let$7 \mathrm{c}$ in archival paraffin-embedded tissue samples which were collected at time of necropsy or biopsy from canine patients with LUTD versus TCC [38]. In archival tissue samples, expression of miR-106b, miR-34a, miR-16, and miR-103b was higher in canine LUTD versus TCC patients. In our current study, no difference in expression of miR-106b and miR-34a was observed in blood or urine samples and miR-103b and miR-16 expression levels were decreased in urine samples from LUTD versus TCC patients. Greater variability in miRNA levels in body fluids versus tissue may account for why differences in miR-34a and miR-106b expression levels were not observed in the current study; within group variances were much higher for these miRNA in the urine and blood analyses described in the current manuscript compared to our previous archival tissue analyses. In case of miR-103b and miR-16, it is possible that the miRNA is produced in the LUTD affected tissue and is retained there, while in TCC, although produced in the tissue, they are then released into the circulation easily. In support of this, several groups have recently shown that some cancer cells can selectively export miRNA [70-72]. Hence selective export of miRNA by in TCC but not LUTD could explain why the levels of these miRNA are lower in the TCC tissue compared to LUTD, but higher in the released urine. Other studies have shown miRNA expression levels can be extremely variable in body fluid specimens $[47,48]$. It is possible the difference in direction in trend of miR-16 and miR-103b in urine versus tissue samples is due, at least in part, to differences in the type of cells present in tissue versus urine samples and their relative proportion. For example, presence and/or proportion of immune cells in the urine samples from the three groups could be a factor. In the current study, 3 out of the 17 (17.6\%) patients with TCC had urinary tract infections at the time of diagnosis. This rate is comparable to a recent study where $25 \%$ of dogs diagnoses with TCC had a positive urine culture prior to beginning chemotherapy [73]. It is likely the archival tissue samples contained a higher proportion of bladder cells compared to the blood and urine samples. Differences in collection and processing that urine and blood samples versus tissue samples went through may have also contributed to the observed differences. While a direct comparison of miRNA expression between 

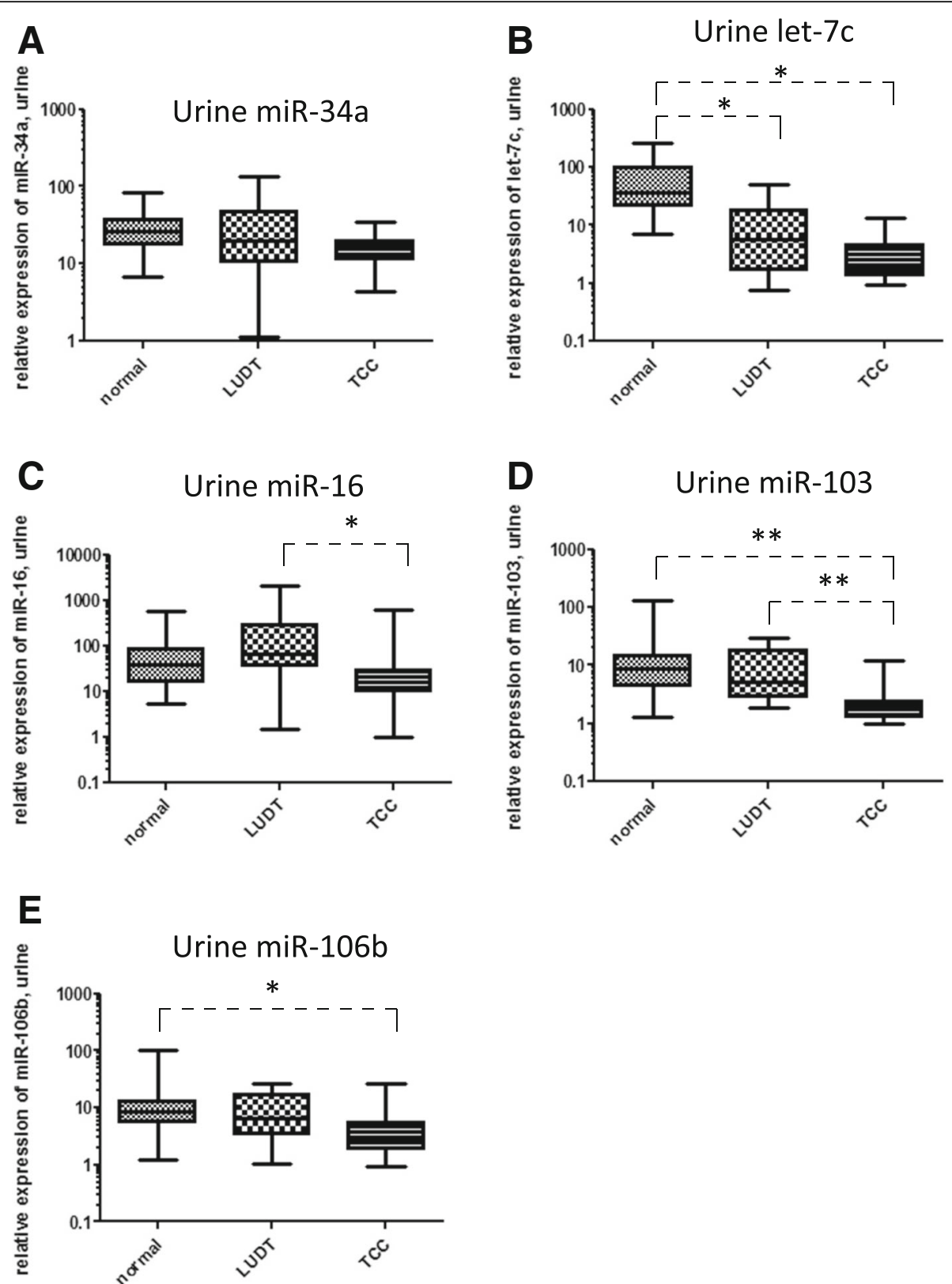

Fig. 5 Comparison of expression levels of miR-34a, let-7c, miR-16, miR-103b, and miR-106b in urine specimens from patients with normal bladders, lower urinary tract disease (LUTD), and transitional cell carcinoma (TCC) of the bladder. One-way ANOVA on ranks identified significant differences in the expression levels of miR-16 and miR-103b in the urine of LUTD vs TCC patients (c and $\mathbf{d}, p<0.05$ and $p<0.005$, respectively), of let-7c levels in the urine of normal vs TCC and LUTD patients (b, $p<0.05$ for both), and of miR-106b levels in the urine of normal vs TCC patients $(\mathbf{e}, p<0.05)$. A statistically significant difference in miR-34a expression levels was not observed between the 3 patient groups (a)

matched tissue, blood, and urine samples is certainly warranted to address the observed discrepancies between the two studies it will likely prove challenging both financially and logistically as bladder biopsies are not routinely performed for canine patients and owners may not be willing to give consent for this procedure due to associated risks.

To our knowledge, extraction and assessment of miRNA from canine urine has not previously been performed, and only a limited number of studies have assessed miRNA expression using human urine samples [30-32]. Urine analysis is ideally suited to biomarker discovery studies for TCC and other urological diseases because urine is in direct contact with the bladder and it can easily be obtained from patients. The fact that we observed statistically significant differences in levels of 4 of the 5 miRNAs assessed in urine specimens (differential expression of miR-103b and miR-16 in LUTD versus 
TCC patients, and differential expression of let-7c and miR-106b in clinically normal versus LUTD and/or TCC patients) versus only 1 in blood specimens (differential expression of miR-103b in clinically normal versus TCC patients) between the 3 patient groups, and also observed progressive loss of coordinated expression of miR-34a, supports the use of urine specimens rather than blood specimens for urological biomarker discovery studies.

\section{Conclusions}

In summary, our data demonstrate an association exists between miR-103b and miR-16 expression levels in urine and TCC, and show that miRNA can be isolated and quantified in canine urine as well as blood specimens. Our results indicate that further investigation of these miRNA as diagnostic non-invasive biomarkers for canine TCC is warranted.

\section{Additional files}

\section{Additional file 1: Table S1. $P$ values for correlation of miRNA} expression in RNA extracted from blood samples from canine patients with normal bladders, Table S2. $P$ values for correlation of miRNA expression in RNA extracted from urine samples from canine patients with normal bladders, Table S3. P values for correlation of miRNA expression in RNA extracted from blood samples from canine patients with LUTD, Table S4. $P$ values for correlation of miRNA expression in RNA extracted from urine samples from canine patients with LUTD, Table S5. $P$ values for correlation miRNA expression in RNA extracted from blood samples from canine patients with TCC, Table S6. $P$ values for correlation of miRNA expression in RNA extracted from urine samples from canine patients with TCC. (DOCX $28 \mathrm{~kb})$

Additional file 2: Table S7. Demographic and miRNA expression data. (XLSX $25 \mathrm{~kb})$

\section{Abbreviations}

AUC: Area under the curve; IACUC: Institutional animal care and use committee; LUTD: Lower urinary tract disease; miRNA: MicroRNA; OR: Odds ratio; ROC: Receiver operating characteristic; SD: Standard deviation; TCC: Transitional cell carcinoma; TNM: Tumor, Lymph Node and Metastasis; UTI: Urinary tract infection

\section{Acknowledgements}

We would like to thank Ms. Teri Guerrero for her help in collecting and processing samples.

\section{Funding}

This study was supported by a grant from the Center for Companion Animal Health, School of Veterinary Medicine, University of California, Davis.

\section{Availability of data and materials}

Demographic and miRNA expression data is available in Additional file 2: Tables S7.

\section{Author contributions}

MSK: Study conception and design, data collection, data interpretation and analysis, drafting and revising manuscript, final approval of manuscript. AZ: Study design, data collection, data interpretation and analysis, drafting and revising manuscript, final approval of manuscript. JLW: Study design, data collection, data interpretation and analysis, drafting and revising manuscript, final approval of manuscript. LEB: Study design, data collection, data interpretation and analysis, drafting and revising manuscript, final approval of manuscript. BDJ: Statistical analyses, final approval of the manuscript. PMG: Study conception and design, data interpretation and analysis, drafting and revising manuscript, final approval of manuscript. RLV: Study conception and design, data collection, data interpretation and analysis, drafting and revising manuscript, final approval of manuscript

\section{Ethics approval and consent to participate}

The UC Davis IACUC and Clinical Trials Review Board approval (protocol number 16538). Written informed consent from owners was obtained as an inclusion criteria for all groups. Dogs were recruited from dogs presenting to the William R. Prichard Veterinary Medical Teaching Hospital and from dogs owned by staff and students at the UC Davis School of Veterinary Medicine.

\section{Competing interests}

None.

\section{Publisher's Note}

Springer Nature remains neutral with regard to jurisdictional claims in published maps and institutional affiliations.

\section{Author details}

'Department of Surgical and Radiological Sciences, School of Veterinary Medicine, University of California, Davis, CA, USA. ${ }^{2}$ Department of Medicine and Epidemiology, School of Veterinary Medicine, University of California, Davis, CA, USA. 'William R. Pritchard Veterinary Medical Teaching Hospital, School of Veterinary Medicine, University of California, Davis, CA, USA. ${ }^{4}$ Department of Public Health Sciences, University of California Davis, Davis, California 95616, USA. ${ }^{5}$ Department of Urology, University of California, Davis, School of Medicine, Sacramento, CA, USA. ${ }^{6}$ Department of Biochemistry and Molecular Medicine, University of California, Davis, School of Medicine, Sacramento, CA, USA. 'VA Northern California Health Care System, Sacramento, CA, USA. ${ }^{8}$ Department of Pharmaceutical and Biomedical Sciences, California Northstate University College of Pharmacy, Elk Grove, CA, USA.

Received: 5 December 2016 Accepted: 7 November 2017

Published online: 15 November 2017

\section{References}

1. Norris AM, Laing EJ, Valli VE, Withrow SJ, Macy DW, Ogilvie GK, Tomlinson J, McCaw D, Pidgeon G, Jacobs RM. Canine bladder and urethral tumors: a retrospective study of 115 cases (1980-1985). J Vet Intern Med. 1992;6(3):145-53.

2. Priester WA, McKay FW. The occurrence of tumors in domestic animals. Natl Cancer Inst Monogr. 1980;54:1-210.

3. Fulkerson CM, Knapp DW. Management of transitional cell carcinoma of the urinary bladder in dogs: a review. Vet J. 2015;205(2):217-25.

4. Mutsaers AJ, Widmer WR, Knapp DW. Canine transitional cell carcinoma. J Vet Intern Med. 2003;17(2):136-44.

5. Knapp DW, Ramos-Vara JA, Moore GE, Dhawan D, Bonney PL, Young KE. Urinary bladder cancer in dogs, a naturally occurring model for cancer biology and drug development. ILAR J. 2014;55(1):100-18.

6. Glickman LT, Raghavan M, Knapp DW, Bonney PL, Dawson MH. Herbicide exposure and the risk of transitional cell carcinoma of the urinary bladder in Scottish terriers. J Am Vet Med Assoc. 2004;224(8):1290-7.

7. Glickman LT, Schofer FS, McKee L, Reif JS, Goldschmidt MH. Epidemiologic study of insecticide exposures, obesity, and risk of bladder cancer in household dogs. J Toxicol Environ Health. 1989;28(4):407-14.

8. Davis BW, Ostrander EA. Domestic dogs and cancer research: a breed-based genomics approach. ILAR J. 2014;55(1):59-68.

9. Owen LN. TNM classification of Tumours in domestic animals. 1st ed. Geneva: World health Organization; 1980.

10. Knapp DW, Glickman NW, Denicola DB, Bonney PL, Lin TL, Glickman LT. Naturally-occurring canine transitional cell carcinoma of the urinary bladder a relevant model of human invasive bladder cancer. Urol Oncol. 2000:5(2):47-59.

11. Chun R, Knapp DW, Widmer WR, Glickman NW, DeNicola DB, Bonney PL. Cisplatin treatment of transitional cell carcinoma of the urinary bladder in dogs: 18 cases (1983-1993). J Am Vet Med Assoc. 1996;209(9):1588-91. 
12. Greene SN, Lucroy MD, Greenberg CB, Bonney PL, Knapp DW. Evaluation of cisplatin administered with piroxicam in dogs with transitional cell carcinoma of the urinary bladder. J Am Vet Med Assoc. 2007;231(7):1056-60.

13. Mohammed SI, Craig BA, Mutsaers AJ, Glickman NW, Snyder PW, deGortari AE, Schlittler DL, Coffman KT, Bonney PL, Knapp DW. Effects of the cyclooxygenase inhibitor, piroxicam, in combination with chemotherapy on tumor response, apoptosis, and angiogenesis in a canine model of human invasive urinary bladder cancer. Mol Cancer Ther. 2003;2(2):183-8.

14. Shapiro W, Kitchell BE, Fossum TW, Couto CG, Theilen G. Cisplatin for treatment of transitional cell and squamous cell carcinomas in dogs. J Am Vet Med Assoc. 1988;193(12):1530-3.

15. Poirier VJ, Forrest LJ, Adams WM, Vail DM. Piroxicam, mitoxantrone, and coarse fraction radiotherapy for the treatment of transitional cell carcinoma of the bladder in 10 dogs: a pilot study. J Am Anim Hosp Assoc. 2004:40(2):131-6.

16. Upton ML, Tangner $\mathrm{CH}$, Payton ME. Evaluation of carbon dioxide laser ablation combined with mitoxantrone and piroxicam treatment in dogs with transitional cell carcinoma. J Am Vet Med Assoc. 2006;228(4):549-52.

17. Bilbrey SA, Withrow SJ, Klein MK, Bennett RA, Norris AM, Gofton N, DeHoff W. Vulvovaginectomy and perineal urethrostomy for neoplasms of the vulva and vagina. Vet Surg. 1989;18(6):450-3.

18. Kamat AM, Hahn NM, Efstathiou JA, Lerner SP, Malmstrom PU, Choi W, Guo CC, Lotan Y, Kassouf W. Bladder cancer. Lancet. 2016;388(10061):2796-810.

19. Bell MD, Yafi FA, Brimo F, Steinberg J, Aprikian AG, Tanguay S, Kassouf W. Prognostic value of urinary cytology and other biomarkers for recurrence and progression in bladder cancer: a prospective study. World J Urol. 2016;34(10):1405-9.

20. Kojima T, Kawai K, Miyazaki J, Nishiyama H. Biomarkers for precision medicine in bladder cancer. Int J Clin Oncol. 2016;

21. Henry CJ. Management of transitional cell carcinoma. Vet Clin North Am Small Anim Pract. 2003;33(3):597-613.

22. Anderson WI, Dunham BM, King JM, Scott DW. Presumptive subcutaneous surgical transplantation of a urinary bladder transitional cell carcinoma in a dog. Cornell Vet. 1989;79(3):263-6.

23. Vignoli M, Rossi F, Chierici C, Terragni R, De Lorenzi D, Stanga M, Olivero D. Needle tract implantation after fine needle aspiration biopsy (FNAB) of transitional cell carcinoma of the urinary bladder and adenocarcinoma of the lung. Schweiz Arch Tierheilkd. 2007;149(7):314-8.

24. Henry CJ, Tyler JW, McEntee MC, Stokol T, Rogers KS, Chun R, Garrett LD, McCaw DL, Higginbotham ML, Flessland KA, et al. Evaluation of a bladder tumor antigen test as a screening test for transitional cell carcinoma of the lower urinary tract in dogs. Am J Vet Res. 2003;64(8):1017-20.

25. Jonas S, Izaurralde E. Towards a molecular understanding of microRNAmediated gene silencing. Nat Rev Genet. 2015;16(7):421-33.

26. Di Leva G, Garofalo M, Croce CM. MicroRNAs in cancer. Annu Rev Pathol. 9:287-314.

27. Mraz M, Malinova K, Mayer J, Pospisilova S. MicroRNA isolation and stability in stored RNA samples. Biochem Biophys Res Commun. 2009;390(1):1-4.

28. Kruhoffer M, Dyrskjot L, Voss T, Lindberg RL, Wyrich R, Thykjaer T, Orntoft TF. Isolation of microarray-grade total RNA, microRNA, and DNA from a single PAXgene blood RNA tube. J Mol Diagn. 2007;9(4):452-8.

29. Brase JC, Wuttig D, Kuner R, Sultmann H. Serum microRNAs as non-invasive biomarkers for cancer. Mol Cancer. 2010;9:306.

30. Puerta-Gil P, Garcia-Baquero R, Jia AY, Ocana S, Alvarez-Mugica M, AlvarezOssorio JL, Cordon-Cardo C, Cava F, Sanchez-Carbayo M. miR-143, miR-222, and miR-452 are useful as tumor stratification and noninvasive diagnostic biomarkers for bladder cancer. Am J Pathol. 180(5):1808-15.

31. Yun SJ, Jeong P, Kim WT, Kim TH, Lee YS, Song PH, Choi YH, Kim IY, Moon SK, Kim WJ. Cell-free microRNAs in urine as diagnostic and prognostic biomarkers of bladder cancer. Int J Oncol. 41(5):1871-8.

32. Yamada Y, Enokida H, Kojima S, Kawakami K, Chiyomaru T, Tatarano S, Yoshino H, Kawahara K, Nishiyama K, Seki N, et al. MiR-96 and miR-183 detection in urine serve as potential tumor markers of urothelial carcinoma: correlation with stage and grade, and comparison with urinary cytology. Cancer Sci. 102(3):522-9.

33. Rosenberg E, Baniel J, Spector Y, Faerman A, Meiri E, Aharonov R, Margel D, Goren $Y$, Nativ O. Predicting progression of bladder urothelial carcinoma using microRNA expression. BJU Int

34. Han Y, Chen J, Zhao X, Liang C, Wang Y, Sun L, Jiang Z, Zhang Z, Yang R, Li $Z$, et al. MicroRNA expression signatures of bladder cancer revealed by deep sequencing. PLoS One. 6(3):e18286.
35. Pignot G, Cizeron-Clairac G, Vacher S, Susini A, Tozlu S, Vieillefond A, Zerbib M, Lidereau R, Debre B, Amsellem-Ouazana $D$, et al. microRNA expression profile in a large series of bladder tumors: identification of a 3-miRNA signature associated with aggressiveness of muscle-invasive bladder cancer. Int J Cancer, 132. (11):2479-91.

36. Kurozumi A, Goto Y, Okato A, Ichikawa T, Seki N. Aberrantly expressed microRNAs in bladder cancer and renal cell carcinoma. J Hum Genet. 2016;

37. Xu Z, YQ Y, Ge YZ, Zhu JG, Zhu M, Zhao YC, LW X, Yang XB, Geng LG, Dou $\mathrm{QL}$, et al. MicroRNA expression profiles in muscle-invasive bladder cancer: identification of a four-microRNA signature associated with patient survival. Tumour Biol. 2015:36(10):8159-66.

38. Vinall RL, Kent MS, deVere White RW. Expression of microRNAs in urinary bladder samples obtained from dogs with grossly normal bladders, inflammatory bladder disease, or transitional cell carcinoma. Am J Vet Res. 73(10):1626-33.

39. Johnson SM, Grosshans H, Shingara J, Byrom M, Jarvis R, Cheng A, Labourier E, Reinert KL, Brown D, Slack FJ. RAS is regulated by the let-7 microRNA family. Cell. 2005;120(5):635-47.

40. He XY, Chen JX, Zhang Z, Li CL, Peng QL, Peng HM. The let-7a microRNA protects from growth of lung carcinoma by suppression of k-Ras and c-Myc in nude mice. J Cancer Res Clin Oncol. 136(7):1023-8.

41. Mayr C, Hemann MT, Bartel DP. Disrupting the pairing between let-7 and Hmga2 enhances oncogenic transformation. Science. 2007;315(5818):1576-9.

42. Shimizu S, Takehara T, Hikita H, Kodama T, Miyagi T, Hosui A, Tatsumi T, Ishida H, Noda T, Nagano H, et al. The let-7 family of microRNAs inhibits Bcl$\mathrm{XL}$ expression and potentiates sorafenib-induced apoptosis in human hepatocellular carcinoma. J Hepatol. 52(5):698-704.

43. Hermeking $\mathrm{H}$. The miR-34 family in cancer and apoptosis. Cell Death Differ. 17(2):193-9.

44. Liao Y, Lonnerdal B. Global microRNA characterization reveals that miR-103 is involved in IGF-1 stimulated mouse intestinal cell proliferation. PLoS One. 5(9):e12976.

45. Aqeilan Rl, Calin GA, Croce CM. miR-15a and miR-16-1 in cancer: discovery, function and future perspectives. Cell Death Differ. 17(2):215-20.

46. Vinall RL, Tepper CG, Ripoll AA, Gandour-Edwards RF, Durbin-Johnson BP, Yap SA, Ghosh PM, deVere White RW. Decreased expression of let-7c is associated with non-response of muscle-invasive bladder cancer patients to neoadjuvant chemotherapy. Genes Cancer. 2016;7(3-4):86-97.

47. Huang $X$, Liang M, Dittmar R, Wang L. Extracellular microRNAs in urologic malignancies: chances and challenges. Int J Mol Sci. 14(7):14785-99.

48. De Guire V, Robitaille R, Tetreault N, Guerin R, Menard C, Bambace N, Sapieha P. Circulating miRNAs as sensitive and specific biomarkers for the diagnosis and monitoring of human diseases: promises and challenges. Clin Biochem. 46(10-11):846-60.

49. Roberts TC, Coenen-Stass AM, Wood MJ. Assessment of RT-qPCR normalization strategies for accurate quantification of extracellular microRNAs in murine serum. PLoS One. 9(2):e89237.

50. Galiveti CR, Rozhdestvensky TS, Brosius J, Lehrach H, Konthur Z. Application of housekeeping npcRNAs for quantitative expression analysis of human transcriptome by real-time PCR. RNA. 2010;16(2):450-61.

51. Jung Y, Huang JZ, Hu J. Biomarker detection in association studies: modeling SNPs simultaneously via logistic ANOVA. J Am Stat Assoc. 2014;109(508):1355-67.

52. Bartel J, Krumsiek J, Theis FJ. Statistical methods for the analysis of highthroughput metabolomics data. Computational and structural biotechnology journal. 2013;4:e201301009.

53. Lu S, Li J, Song C, Shen K, Tseng GC. Biomarker detection in the integration of multiple multi-class genomic studies. Bioinformatics. 2010;26(3):333-40.

54. Smilde AK, Jansen JJ, Hoefsloot HC, Lamers RJ, van der Greef J, Timmerman ME. ANOVA-simultaneous component analysis (ASCA): a new tool for analyzing designed metabolomics data. Bioinformatics. 2005;21(13):3043-8.

55. Bauer C, Kleinjung F, Smith CJ, Towers MW, Tiss A, Chadt A, Dreja T, Beule $\mathrm{D}, \mathrm{Al}$-Hasani $\mathrm{H}$, Reinert $\mathrm{K}$, et al. Biomarker discovery and redundancy reduction towards classification using a multi-factorial MALDI-TOF MS T2DM mouse model dataset. BMC bioinformatics. 2011;12:140.

56. Poon TC, Hui AY, Chan HL, Ang IL, Chow SM, Wong N, Sung JJ. Prediction of liver fibrosis and cirrhosis in chronic hepatitis B infection by serum proteomic fingerprinting: a pilot study. Clin Chem. 2005;51(2):328-35.

57. Xiao S, Wang J, Xiao N. MicroRNAs as noninvasive biomarkers in bladder cancer detection: a diagnostic meta-analysis based on qRT-PCR data. Int J Biol Markers. 2016;0 
58. Armstrong DA, Green BB, Seigne JD, Schned AR, Marsit CJ. MicroRNA molecular profiling from matched tumor and bio-fluids in bladder cancer. Mol Cancer. 2015;14:194.

59. Ralla B, Stephan C, Meller S, Dietrich D, Kristiansen G, Jung K. Nucleic acidbased biomarkers in body fluids of patients with urologic malignancies. Crit Rev Clin Lab Sci. 2014;51(4):200-31.

60. Zhou H, Tang K, Xiao H, Zeng J, Guan W, Guo X, Xu H, Ye Z. A panel of eight-miRNA signature as a potential biomarker for predicting survival in bladder cancer. J Exp Clin Cancer Res. 2015;34:53.

61. Jiang X, Du L, Duan W, Wang R, Yan K, Wang L, Li J, Zheng G, Zhang X, Yang $Y$, et al. Serum microRNA expression signatures as novel noninvasive biomarkers for prediction and prognosis of muscle-invasive bladder cancer. Oncotarget. 2016;

62. Geng L, Sun B, Gao B, Wang Z, Quan C, Wei F, Fang XD. MicroRNA-103 promotes colorectal cancer by targeting tumor suppressor DICER and PTEN. Int J Mol Sci. 2014;15(5):8458-72.

63. Hong Z, Feng Z, Sai Z, Tao S. PER3, a novel target of miR-103, plays a suppressive role in colorectal cancer in vitro. BMB Rep. 2014;47(9):500-5.

64. Chen HY, Lin YM, Chung HC, Lang YD, Lin CJ, Huang J, Wang WC, Lin FM, Chen Z, Huang HD, et al. miR-103/107 promote metastasis of colorectal cancer by targeting the metastasis suppressors DAPK and KLF4. Cancer Res. 2012:72(14):3631-41.

65. Nana-Sinkam SP, Croce CM. MicroRNA in chronic lymphocytic leukemia: transitioning from laboratory-based investigation to clinical application. Cancer Genet Cytogenet. 2010;203(2):127-33.

66. Aqeilan RI, Calin GA, Croce CM. miR-15a and miR-16-1 in cancer: discovery, function and future perspectives. Cell Death Differ. 2010;17(2):215-20.

67. Cho WC. OncomiRs: the discovery and progress of microRNAs in cancers. Mol Cancer. 2007;6:60.

68. Shalgi R, Lieber D, Oren M, Pilpel Y. Global and local architecture of the mammalian microRNA-transcription factor regulatory network. PLoS Comput Biol. 2007;3(7):e131.

69. Budd WT, Weaver DE, Anderson J, Zehner ZE. microRNA dysregulation in prostate cancer: network analysis reveals preferential regulation of highly connected nodes. Chem Biodivers. 2012;9(5):857-67.

70. Falcone G, Felsani A, D'Agnano I. Signaling by exosomal microRNAs in cancer. J Exp Clin Cancer Res. 2015:34:32.

71. Ohshima K, Inoue K, Fujiwara A, Hatakeyama K, Kanto K, Watanabe Y, Muramatsu K, Fukuda Y, Ogura S, Yamaguchi K, et al. Let-7 microRNA family is selectively secreted into the extracellular environment via exosomes in a metastatic gastric cancer cell line. PLoS One. 2010;5(10):e13247.

72. Ostenfeld MS, Jeppesen DK, Laurberg JR, Boysen AT, Bramsen JB, PrimdalBengtson B, Hendrix A, Lamy P, Dagnaes-Hansen F, Rasmussen MH, et al. Cellular disposal of miR23b by RAB27-dependent exosome release is linked to acquisition of metastatic properties. Cancer Res. 2014;74(20):5758-71.

73. Budreckis DM, Byrne BA, Pollard RE, Rebhun RB, Rodriguez CO, Jr., Skorupski KA: Bacterial urinary tract infections associated with transitional cell carcinoma in dogs. Journal of veterinary internal medicine / American College of Veterinary Internal Medicine 2015, 29(3):828-833.

\section{Submit your next manuscript to BioMed Central and we will help you at every step:}

- We accept pre-submission inquiries

- Our selector tool helps you to find the most relevant journal

- We provide round the clock customer support

- Convenient online submission

- Thorough peer review

- Inclusion in PubMed and all major indexing services

- Maximum visibility for your research

Submit your manuscript at www.biomedcentral.com/submit
Biomed Central 